\title{
Comparison of the Thesslay Test and McMurray Test: A Systematic Review of Comparative Diagnostic Studies
}

\section{Jenny Alexanders ${ }^{1 *}$, Anna Anderson ${ }^{2}$, Sarah Henderson ${ }^{1}$ and Ulf Clausen ${ }^{3}$}

${ }^{1}$ Sport, Health and Sciences Department, The University of Hull, Washburn Building, Cottingham Road, Hull, United Kingdom

${ }^{2}$ Leeds Teaching Hospitals, Beckett Street, Leeds, LS9 7TF, United Kingdom

${ }^{3}$ Dr Hill and Partners, Beverly Health Practice, Manor Road, Hull, HU17 7BZ, United Kingdom

\begin{abstract}
Background: The Thessaly test is a relatively recently developed meniscal test; therefore research compared to other meniscal tests is somewhat limited. In addition, a systematic review comparing the Thessaly's test with a long standing test such as the McMurray test has not been previously conducted.

Objective: To systematically identify and appraise all empirical studies comparing the diagnostic accuracy of the Thessaly test and McMurray test.

Procedure: Eligible studies were identified through a rigorous search of ScienceDirect, CINAHL Plus, Pubmed, PEDro, EMBASE and Cochrane Library from January 2004 until August 2014. Full English reports of studies investigating the accuracy of the Thessaly test and McMurray test. Quality Assessment of Studies of Diagnostic Accuracy (QUADAS) scores were completed on each selected article.

Results: The Thessaly test reported to have higher diagnostic accuracy values (61-96\%) compared to the McMurray test $(56-84 \%)$. Although McMurray test showed to have higher sensitivity in the detection of lateral meniscal tears, the Thessaly reported to more sensitive for medial and higher specificity values for both medial and lateral tears.

Limitations: All the included studies have considerable limitations related to inclusion and exclusion criteria and recording of test outcomes.

Conclusion: Higher strength of evidence studies are warranted to ensure a more robust data collection of information in addition to further investigate the diagnostic accuracy of such tests.
\end{abstract}

Keywords: Thessaly test; Diagnostic accuracy; Meniscal tears; McMurrays test.

\section{Introduction}

Meniscal injuries are common in both sporting and non-sporting populations, frequently causing significant pain and functional limitations [1]. Furthermore meniscal injuries impose undue load and stress on the adjacent articular cartilage, predisposing the articular cartilage to damage and thus increasing the risk of early onset of osteoarthritis [2]. Research has demonstrated that injuries which occur within avascular regions of the menisci do not heal spontaneously [3]. Early detection of meniscal injuries is therefore of paramount importance to enable rapid implementation of appropriate treatment interventions and to reduce the risk of complications [4]. Identifying clinically useful methods for detecting meniscal tears has therefore attracted much attention from physiotherapists and doctors for many years [5].

Arthroscopy is widely considered the gold standard in the assessment of meniscal injuries, with evidence suggesting magnetic resonance imaging (MRI) is the most accurate non-invasive tool for detecting meniscal injuries [2]. The diagnostic value of MRI has however been questioned, particularly when used in isolation [6]. This, together with the high cost of MRI, means physical examination tests have a particularly important role to play in the detection of meniscal injuries in clinical practice [5]. Numerous such tests have been developed; however there is on-going controversy regarding their diagnostic value [5-11]

Of all the meniscal tests available the McMurray test is thought to be the most widely used [11]. This test, first described in 1940, involves the examiner applying a valgus/varus stress and external/internal rotation to the patient's knee during passive knee extension [7]. In contrast the Thessaly Test is a much more recently developed test, first introduced in 2005, and requires the patient to actively rotate his/her knee in standing whilst maintaining either $5^{\circ}$ or $20^{\circ}$ of knee flexion [8]. From a functional perspective the Thessaly test may therefore be considered superior to the McMurray test because it is performed in a functional weight bearing position as opposed to a non-functional position such as lying. It has been suggested that rotation of the knee at $20^{\circ}$ of flexion in a unilateral stance position causes meniscal fragments to be squeezed apart, stimulating nociceptors within the outer parts of the menisci and eliciting a pain response [8]. The increased load achieved through use of a standing position has been suggested to enable the detection of even small meniscal tears. However Akseki et al. have suggested that the McMurray test is superior to weight bearing meniscal tests for detecting degenerative meniscal tears. Because the McMurray's test is the most long standing and commonly used meniscal test, compared to other tests such as Apleys and joint line tenderness [9], this test was therefore selected to be used as a comparison with the Thessaly's test.

*Corresponding author: Jenny Alexanders, Sport, Health and Sciences Department, The University of Hull, Washburn Building, Cottingham Road, Hull, HU67RX, United Kingdom, Tel: 07557388811; E-mail: J.Alexanders@hull.ac.uk

Received: December 21, 2015; Accepted: March 17, 2016; Published: March 24, 2016

Citation: Alexanders J, Anderson A, Henderson S, Clausen U (2016) Comparison of the Thesslay Test and McMurray Test: A Systematic Review of Comparative Diagnostic Studies. Physiother Rehabil 1: 104. doi: 10.4172/2573-0312.1000104

Copyright: ( 2016 Alexanders J, et al. This is an open-access article distributed under the terms of the Creative Commons Attribution License, which permits unrestricted use, distribution, and reproduction in any medium, provided the original author and source are credited. 
Although the Thessaly Test has not been as extensively researched as the McMurray test a meta-analysis performed in 2010 suggested that the Thessaly test has higher test quality than the McMurray test [5]. Furthermore, subsequent research has reported the Thessaly test to have a sensitivity of $89-92 \%$ [10], while the McMurray test has been reported to have a sensitivity of only $76 \%$ [11]. The specificity values reported for the Thessaly and McMurray tests are however comparable, being $96-97 \%$ and $99 \%$ respectively [10].

To the authors' knowledge no systematic reviews have compared the relatively recently developed Thessaly test to a more long standing test such as the McMurray test. Such a review could provide valuable information for assisting the detection of meniscal tears in clinical practice. The objective of the present systematic review was therefore to determine the diagnostic accuracy of the Thessaly test compared to the McMurray test for the detection of meniscal tears.

\section{Methods}

The conduct and reporting of this systematic review have been based on guidelines provided by the PRISMA statement [12].

\section{Protocol and registration}

No prior protocol was published.

\section{Data sources}

A thorough search of the following electronic databases was performed using the terms displayed in (Table 1). Pubmed, Cochrane Library, CINAHL Plus, EMBASE, ScienceDirect and PEDro. The reference lists of the retrieved articles were also hand searched. All searches were performed by one investigator (JA).

\section{Trial selection}

All articles identified by the searches were assessed for eligibility using the criteria described below. Full text copies of any potentially relevant articles were obtained to confirm eligibility. The trial selection was performed by one investigator (JA).

\section{Eligibility criteria}

The electronic search results were considered for inclusion if they were empirical quantitative studies which investigated the sensitivity and specificity values of the Thessaly and McMurray tests for detecting meniscal tears. Only studies which compared these two tests were included, with exclusion of studies investigating the Thessaly test or McMurray test in isolation. This was to maximise consistency of variables such as the patient population, setting for the two different tests. Studies were rejected if there were no sensitivity or specificity values recorded. In addition, any studies that did not use a reference standard such as MRI or arthroscopy were also rejected.

Studies were only considered for inclusion if they were full text papers published in English language dated from $2^{\text {nd }}$ January 2004 to $2^{\text {nd }}$ January 2015. Abstracts alone and systematic reviews were excluded; however the reference lists of any relevant systematic reviews were screened for potentially relevant studies. Full text copies of studies reported in conference proceedings were retrieved if available.

\section{Data extraction}

Data regarding the characteristics, participants, interventions, outcome measures and results of each study selected for inclusion were extracted using a standardised form (Table S1). This form was completed by one reviewer (JA) and verified by a two independent reviewers (AA and $\mathrm{SH}$ ).

\begin{tabular}{|c|c|c|}
\hline Database & Search strategy & Results \\
\hline PubMed & $\begin{array}{l}\text { ((menisci [tw] AND test [tw]) OR diagnostic [tw] OR } \\
\text { Thessaly Test OR McMurrays Test [tw] OR accuracy[tw]) } \\
\text { AND ((quantitative [tw] AND design [tw]) OR clinical [tw]) } \\
\text { AND "humans"[MeSH Terms] AND English[lang] AND }\end{array}$ & 140 \\
\hline $\begin{array}{c}\text { Cochrane } \\
\text { Library }\end{array}$ & $\begin{array}{c}\text { ((menisci AND test) OR diagnostic OR Thessaly Test OR } \\
\text { McMurrays Test OR accuracy ) AND ((quantitative AND } \\
\text { design ) OR clinical) }\end{array}$ & 25 \\
\hline CINAHL Plus & $\begin{array}{c}\text { ((menisci AND test ) OR diagnostic OR Thessaly Test OR } \\
\text { McMurrays Test OR accuracy ) AND ((quantitative AND } \\
\text { design ) OR clinical ) }\end{array}$ & 46 \\
\hline Embase & $\begin{array}{c}\text { 'menisci ‘/ test OR 'diagnostic’/exp OR 'Thessaly Test'/ } \\
\text { exp OR'McMurrays Test'/exp OR ‘accuracy’/exp OR } \\
\text { quantitative design'/exp OR 'clinical' }\end{array}$ & 16 \\
\hline ScienceDirect & $\begin{array}{c}\text { ("menisci test" OR diagnostic OR "Thessaly Test" OR } \\
\text { McMurrays Test OR accuracy) AND ("quantitative design" } \\
\text { OR clinical) }\end{array}$ & 735 \\
\hline PEDro & menisci AND test AND Thessaly Test McMurrays Test & 8 \\
\hline
\end{tabular}

Table 1: Electronic resource search strategy and results.

\section{Study synthesis and appraisal}

Each study selected for inclusion was assessed by three independent reviewers (JA, and SH) using the Quality Assessment Diagnostic Accuracy Studies (QUADAS) $[13,14]$. The QUADAS is a quality assessment checklist specifically developed for use in studies investigating diagnostic accuracy. It comprises 14 items which are presented as questions that must be answered using either "yes", "no", or "unclear" (Table S2) [14]. The original authors of the QUADAS emphasised that the tool does not provide a quality score [14]; however subsequent authors have advocated awarding all the "yes" answers 1 point to yield an overall QUADAS score [13]. Furthermore a cut-off score of 10 has been suggested, with scores of 10 or more indicating high quality and score of less than 10 indicating low quality (14). It was therefore decided to adopt this approach for the present study. Although there is an updated version of the QUADAS tool, the original QUADAS tool is still considered to be a reliable quality assessment checklist [15]. Following the reviewed studies, any discrepancies between the independent reviewers were resolved by consensus; in addition a third independent reviewer (UC) was available to address any disagreements if required.

\section{Diagnostic accuracy measures}

Results from the included studies were directly transferred and assembled together showing sensitivity, specificity and diagnostic accuracy values for the Thessaly and McMurray's test.

\section{Results}

\section{Study selection}

The study selection process and number of results retrieved from each electronic search are shown in Figure 1 and Table 1 respectively. Out of the 970 articles retrieved in the electronic searches, 293 were duplicates, leaving a total of 677 potentially relevant articles. No additional articles were identified through hand-searching; therefore 677 articles were screened for possible inclusion. Of these articles, 634 were excluded based on their titles and abstracts alone. A detailed assessment of the full-text versions of the remaining 43 articles resulted in exclusion of a further 39 articles. Due to a lack of inclusion of the Thessaly Test, 37 of these were excluded, whilst the remaining article was excluded because it did not provide sensitivity and specificity values for the Thessaly or McMurray tests considered individually [16]. Another study by Harrison, Abel \& Gibson (2009), was also removed due to the 
study not including the McMurray's test [17]. The remaining 4 articles [8,18-20], which described 4 separate studies, were all included in this review. The characteristics of these studies are presented in Table 2.

\section{Study design}

Konan et al. [18], Mirzatolooei et al. [19] and Goossens et al. [20] all employed a diagnostic accuracy study. Karachalios et al. employed a randomised two group, pre and post-test design [8].

\section{Participants}

A total of 1192 individuals participated in the studies included in this review. 758 of the participants were male and the age ranged 16 years [18] to 56 years [8]. The inclusion and exclusion criteria used varied between the included studies. Three studies included participants with suspected meniscal tears $[8,18,20]$. In contrast Mirzatolooei et al. included participants with confirmed ACL tears who were awaiting surgical repair [19]. All studies included both inclusion and exclusion criteria as a requisite to clinically diagnose a meniscal tear $[8,18-20]$. Duration of symptoms were only reported by two of the included studies $[8,20]$, but this varied considerably from more than 3 months [20] weeks to less than 4 weeks [8]. For the other studies, no specific time scales were reported $[18,19]$.

\section{Interventions}

All four studies investigated the Thessaly test performed at $20^{\circ}$ of knee flexion $[8,18-20]$. Two studies also investigated the Thessaly test performed at $5^{\circ}$ of knee flexion $[8,18]$. All four studies included the McMurray test $[8,18-20]$. In addition one study included the Apley test
[8] and three studies included the joint line tenderness test $[8,18,19]$. The reference standard used to confirm a meniscal tear varied between studies, with Karachalios et al. using MRI [8], whilst all the other studies used arthroscopy [18-20].

\section{Findings}

The principal aim of the included studies was to evaluate the diagnostic accuracy of the Thessaly test in detecting knee meniscal injuries compared to more established tests such as the McMurray test. Three of the included studies concluded that the Thessaly test performed in isolation is not an accurate test for determining the presence of meniscal tears [18-20], whereas one of the included studies reported that the Thessaly test is highly accurate when used for this purpose [8]. One study also concluded that performing the Thessaly test and McMurray test together does not provide an accurate method of detecting meniscal injuries [20], whilst another concluded that combining the Thessaly test with other clinical test does help improve diagnostic accuracy [18].

All the included studies investigated the McMurray test in addition to the Thessaly test $[8,18-20]$. One study also included the Apley test [8] and three studies included the joint line tenderness test $[8,18,19]$. All four studies used the Thessaly test performed at $20^{\circ}$ of knee flexion $[8,18-20]$. Two studies also performed the Thessaly test at $5^{\circ}$ of knee flexion $[8,18]$. As demonstrated in Table 3 the diagnostic parameters of sensitivity, specificity and accuracy varied considerably for both the Thessaly test and McMurray test between the different studies. Accuracy values for the Thessaly test performed at $20^{\circ}$ ranged from $58 \%$ to $94 \%$ for medial meniscal and for lateral 46-96\% [8,18-20] and the accuracy

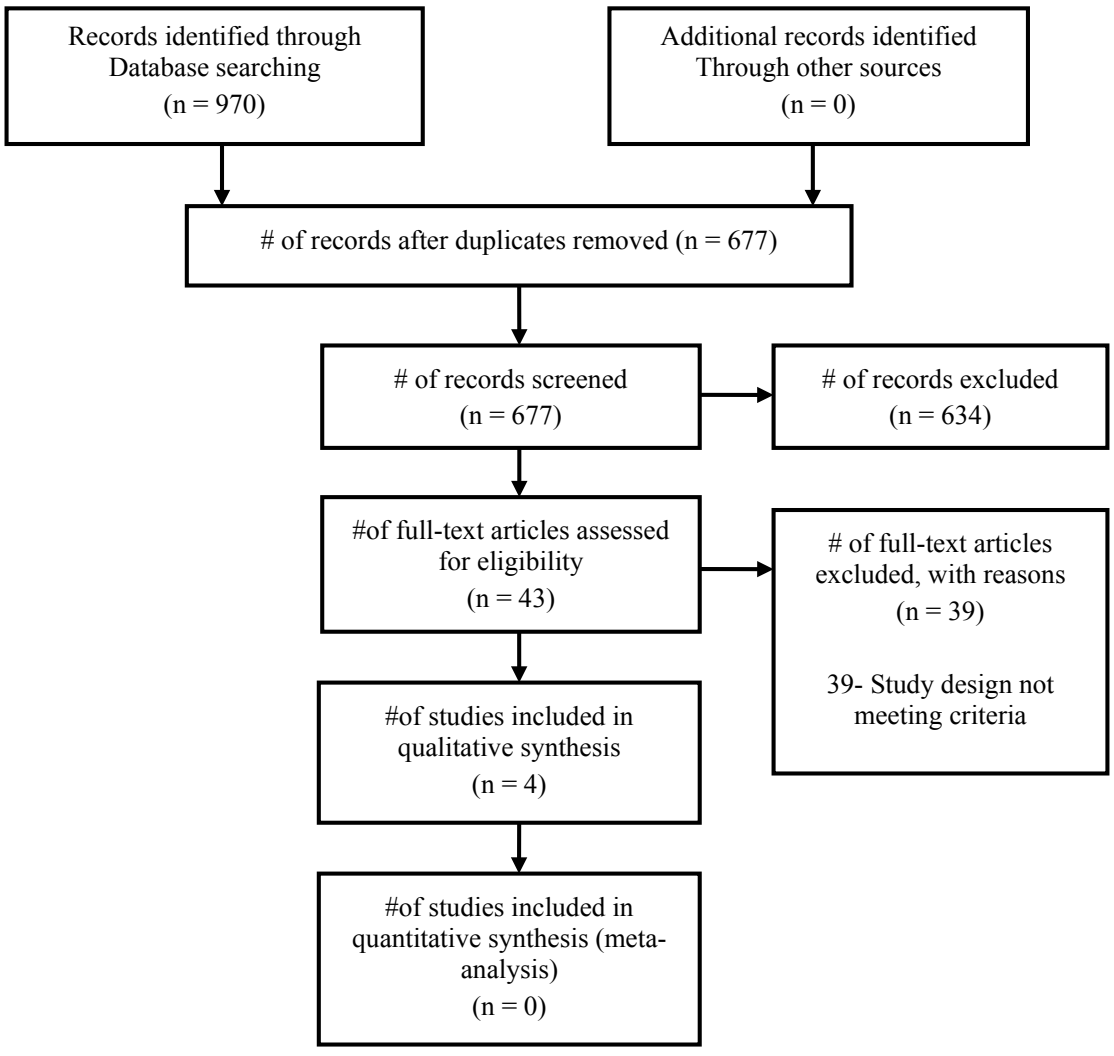

Figure 1: PRISMA flow diagram of search strategy. 
Citation: Alexanders J, Anderson A, Henderson S, Clausen U (2016) Comparison of the Thesslay Test and McMurray Test: A Systematic Review of Comparative Diagnostic Studies. Physiother Rehabil 1: 104. doi: 10.4172/2573-0312.1000104

Page 4 of 7

\begin{tabular}{|c|c|c|c|c|c|c|}
\hline Study & Design & Participants & Inclusion/exclusion criteria & Physical examination & $\begin{array}{l}\text { Reference } \\
\text { standard }\end{array}$ & Results \\
\hline $\begin{array}{l}\text { Karachalios } \\
\text { et al. [18] }\end{array}$ & $\begin{array}{l}\text { Randomised } \\
\text { two group pre/ } \\
\text { post study }\end{array}$ & \begin{tabular}{|c|} 
Group A: 213 \\
participants with \\
suspected meniscal \\
injuries (157 males, 56 \\
females). \\
Mean age 29.4 years \\
(range 18-55 years). \\
Group B: 197 \\
participants with no \\
knee pathologies (144 \\
males, 53 females). \\
Mean age 31.1 years \\
(range 18-56 years). \\
\end{tabular} & $\begin{array}{l}\text { Group A inclusion criteria: } \\
\text { Diagnosis of suspected } \\
\text { meniscal tear based on } \\
\text { clinical history. } \\
\text { Group A exclusion criteria: } \\
\text { Multiple knee injuries, } \\
\text { history of knee surgery, knee } \\
\text { osteoarthritis or cartilage } \\
\text { damage. } \\
\text { - Neurological/ } \\
\text { musculoskeletal } \\
\text { degeneration. } \\
\text { - Synovial disorder } \\
\text { Within the first } 4 \text { weeks post- } \\
\text { injury. } \\
\text { Group B inclusion criteria: } \\
\text { No knee symptoms or history } \\
\text { of knee disorders. } \\
\text { Attending an outpatient clinic for } \\
\text { lumbar spine or shoulder } \\
\text { disorder. }\end{array}$ & $\begin{array}{l}\text { All participants } \\
\text { underwent a clinical } \\
\text { examination performed } \\
\text { by two experienced } \\
\text { examiners and } \\
\text { two inexperienced } \\
\text { examiners, which } \\
\text { included application of } \\
\text { the Apley, McMurray, } \\
\text { JLT and Thessaly tests. } \\
\text { In group A the Thessaly } \\
\text { test was performed on } \\
\text { the unaffected knee } \\
\text { followed by the affected } \\
\text { knee. } \\
\text { The Thessaly test was } \\
\text { performed at both } 5^{\circ} \\
\text { and } 20^{\circ} \text {. }\end{array}$ & $\begin{array}{l}\text { Following } \\
\text { the physical } \\
\text { examination } \\
\text { all participants } \\
\text { underwent an MRI } \\
\text { scan. } \\
\text { Participants in } \\
\text { group A but not } \\
\text { group B also } \\
\text { underwent knee } \\
\text { arthroscopy } \\
\text { for therapeutic } \\
\text { purposes but only } \\
\text { the MRI scan } \\
\text { results were used } \\
\text { as the reference } \\
\text { standard. }\end{array}$ & $\begin{array}{l}\text { For medial and lateral meniscal } \\
\text { injuries respectively: } \\
\text { - The Thessaly test performed } \\
\text { at } 5^{\circ} \text { had an overall accuracy } \\
\text { of } 86 \% \text { and } 90 \% \text {, a sensitivity } \\
66 \% \text { and } 81 \% \text { and a } \\
\text { specificity of } 96 \% \text { and } 91 \% \text {. } \\
\text { The Thessaly test performed } \\
\text { at } 20^{\circ} \text { had an overall } \\
\text { accuracy of } 94 \% \text { and } 96 \% \text {, a } \\
\text { sensitivity of } 89 \% \text { and } 92 \% \\
\text { and a specificity of } 97 \% \text { and } \\
96 \% \text {. } \\
\text { The McMurray test had an overall } \\
\text { accuracy of } 78 \% \text { and } 84 \%, \text { a } \\
\text { sensitivity of } 48 \% \text { and } 65 \% \text { and } \\
\text { a specificity of } 94 \% \text { and } 86 \% \text {. }\end{array}$ \\
\hline $\begin{array}{l}\text { Konan et al. } \\
{[19]}\end{array}$ & $\begin{array}{l}\text { Diagnostic } \\
\text { accuracy study }\end{array}$ & $\begin{array}{c}109 \text { participants with } \\
\text { suspected meniscal } \\
\text { injuries (80 males, } 29 \\
\text { females). } \\
\text { Mean age } 39 \text { years } \\
\text { (range 16-56 years). }\end{array}$ & $\begin{array}{l}\text { Inclusion criteria: } \\
\text { - } \text { Awaiting arthroscopy for } \\
\text { suspected meniscal injury. } \\
\text { Diagnosis of suspected } \\
\text { meniscal injury based on } \\
\text { clinical history, physical } \\
\text { examination and MRI scan } \\
\text { results. } \\
\text { Exclusion criteria: } \\
\text { Not consenting to performing } \\
\text { the Thessaly test. } \\
\text { No confident performing the } \\
\text { Thessaly test due to anxiety } \\
\text { or pain. }\end{array}$ & $\begin{array}{l}\text { All participants } \\
\text { underwent a clinical } \\
\text { examination performed } \\
\text { by one investigator, } \\
\text { blinded to the MRI } \\
\text { scan results, which } \\
\text { included application of } \\
\text { the McMurray, JLT and } \\
\text { Thessaly tests. } \\
\text { The Thessaly test was } \\
\text { performed at both } 5^{\circ} \\
\text { and } 20^{\circ} \text {. }\end{array}$ & $\begin{array}{c}\text { Following } \\
\text { the physical } \\
\text { examination } \\
\text { all participants } \\
\text { underwent knee } \\
\text { arthroscopy and } \\
\text { MRI were used } \\
\text { as the reference } \\
\text { standard. }\end{array}$ & $\begin{array}{l}\text { For medial and lateral meniscal } \\
\text { injuries respectively: } \\
\text { - } \\
\text { The Thessaly test performed } \\
\text { at } 5^{\circ} \text { had an overall accuracy } \\
\text { of } 49 \% \text { and } 71 \% \text { and a } \\
\text { specificity of } 68 \% \text { and } 89 \% \text {. } \\
\text { No sensitivity values were } \\
\text { recorded for this test. } \\
\text { - The Thessaly test performed } \\
\text { at } 20^{\circ} \text { had an overall } \\
\text { accuracy of } 61 \% \text { and } 80 \% \text {, a } \\
\text { sensitivity of } 59 \% \text { and } 31 \% \\
\text { and a specificity of } 67 \% \text { and } \\
95 \% \text {. } \\
\text { The McMurray test had an overall } \\
\text { accuracy of } 57 \% \text { and } 77 \%, \text { a } \\
\text { sensitivity of } 50 \% \text { and } 21 \% \text { and } \\
\text { a specificity of } 77 \% \text { and } 94 \% \text {. }\end{array}$ \\
\hline $\begin{array}{l}\text { Mirzatolooei } \\
\text { et al. [20] }\end{array}$ & $\begin{array}{l}\text { Diagnostic } \\
\text { accuracy study }\end{array}$ & $\begin{array}{l}80 \text { participants with } \\
\text { ACL injuries (76 } \\
\text { males, } 4 \text { females). } \\
\text { Mean age } 26.62 \text { years } \\
\text { (range 17-40 years). }\end{array}$ & $\begin{array}{l}\text { Inclusion criteria: } \\
\text { - } \quad \text { ACL injury evident on MRI } \\
\text { scan. } \\
\text { - Awaiting ACL reconstruction } \\
\text { surgery. } \\
\text { Exclusion criteria: } \\
\text { - Over } 40 \text { years old. } \\
\text { Multi-ligamentous knee } \\
\text { injury, previous knee surgery } \\
\text { or history of anterior knee } \\
\text { pain. } \\
\text { - Rheumatologic disease. } \\
\text { Degenerative changes on knee } \\
\text { radiographs. }\end{array}$ & $\begin{array}{l}\text { All participants } \\
\text { underwent a clinical } \\
\text { examination performed } \\
\text { by two orthopaedic } \\
\text { residents, which } \\
\text { included application of } \\
\text { the McMurray, JLT and } \\
\text { Thessaly tests. } \\
\text { The Thessaly test was } \\
\text { performed at } 20^{\circ} \text { only. }\end{array}$ & \begin{tabular}{|l|} 
Following \\
the physical \\
examination \\
all participants \\
underwent knee \\
arthroscopy \\
for therapeutic \\
and diagnostic \\
purposes. The \\
arthroscopy results \\
were used as the \\
reference standard.
\end{tabular} & $\begin{array}{l}\text { The Thessaly test performed at } 20^{\circ} \\
\text { had an overall accuracy of } 60 \% \text {, a } \\
\text { specificity of } 40 \% \text { and a sensitivity } \\
\text { of } 79 \% \text {. } \\
\text { The McMurray test had a specificity } \\
\text { of } 91 \% \text { and a sensitivity of } 51 \% \text {. The } \\
\text { overall diagnostic accuracy of the } \\
\text { McMurray test was not reported. } \\
\text { All values provided were for medial } \\
\text { and lateral meniscal injuries } \\
\text { considered together, with no values } \\
\text { being provided for medial or lateral } \\
\text { meniscal injuries considered in } \\
\text { isolation. }\end{array}$ \\
\hline $\begin{array}{l}\text { Goossens } \\
\text { et al. } \\
{[21]}\end{array}$ & $\begin{array}{l}\text { Diagnostic } \\
\text { accuracy stud }\end{array}$ & $\begin{array}{l}593 \text { participants with } \\
\text { suspected meniscal } \\
\text { injuries ( } 301 \text { males, } \\
292 \text { females). } \\
\text { Mean age } 49.4 \\
\text { years (age range not } \\
\text { provided). }\end{array}$ & $\begin{array}{l}\text { Inclusion criteria: } \\
\text { - At least } 18 \text { years old. } \\
\text { Referred to hospital for } \\
\text { arthroscopy due to a } \\
\text { possible meniscal tear. } \\
\text { Exclusion criteria: } \\
\text { Knee surgery in the previous } \\
\quad 3 \text { months. } \\
\text { Neurological disease. }\end{array}$ & $\begin{array}{l}\text { All participants } \\
\text { underwent a } \\
\text { clinical examination } \\
\text { performed by one of } \\
\text { seven experienced } \\
\text { physiotherapist, which } \\
\text { included application } \\
\text { of the Thessaly } \\
\text { test followed by the } \\
\text { McMurray test. } \\
\text { The Thessaly test was } \\
\text { performed at } 20^{\circ} \text { only. }\end{array}$ & $\begin{array}{l}\text { Following } \\
\text { the physical } \\
\text { examination } \\
\text { all participants } \\
\text { underwent knee } \\
\text { arthroscopy and } \\
\text { the arthroscopy } \\
\text { results were used } \\
\text { as the reference } \\
\text { standard. }\end{array}$ & $\begin{array}{l}\text { For medial and lateral meniscal } \\
\text { injuries respectively: } \\
\text { - The Thessaly test performed } \\
\text { at } 20^{\circ} \text { had an overall } \\
\text { accuracy of } 58 \% \text { and } 46 \% \text {, a } \\
\text { sensitivity of } 64 \% \text { and } 64 \% \\
\text { and a specificity of } 45 \% \text { and } \\
40 \% \text {. } \\
\text { The McMurray test had an overall } \\
\text { accuracy of } 59 \% \text { and } 43 \% \text {, a } \\
\text { sensitivity of } 69 \% \text { and } 72 \% \text { and a } \\
\text { specificity of } 37 \% \text { and } 34 \% \text {. }\end{array}$ \\
\hline
\end{tabular}

Table 2: Characteristics of the included studies. ACL- anterior cruciate ligament, JLT- joint line tenderness, MRI- magnetic resonance imaging

values for the McMurrays test ranged from $56 \%$ to $78 \%$ for medial and for lateral was $43 \%$ to $84 \%$ indicating that the Thessalys test showed an overall higher ${ }^{\circ}$ diagnostic accuracy rate compared to McMurrays. Sensitivity values for medial meniscus for the Thessaly test ranged from $59 \%$ to $96.1 \%$. Sensitivity values for the McMurrays test ranged from $48 \%$ to $96.1 \%$. Sensitivity values for the lateral meniscus for the Thessalys test ranged from $31 \%$ to $92 \%$ compared to the McMurrays which ranged from $21 \%$ to $96.1 \%$ which would indicate that the Thessaly test appeared more accurate from a sensitivity value for the medial and lateral meniscus compared to McMurrays. Specificity values 
for the medial meniscus for Thessalys test ranged from $38.4 \%$ to $97.7 \%$ compared to McMurrays which ranged from $33.3 \%$ to $94 \%$. Specificty for lateral for Thessalys test ranged from $38.4 \%$ to $97.7 \%$ compared to McMurays which ranged from $33.3 \%$ to $94 \%$ which would indicate that Thessalys has a higher specificity value both medial and lateral meniscus compared to McMurrays. Sensitivity and specificity values are shown in Table 4.

The QUADAS scores for the included studies are displayed in Table 3.All four studies scored a 10 or above for the QUADAS scale [8,18-20], suggesting they have high methodological quality. One study scored 10 [18], another study scored 11 [20] one study scored 12 [8] whilst the final study scored 13 [19].

\section{Discussion}

The studies included in this systematic review provide preliminary evidence that the Thessaly test is a clinically useful test when compared to the McMurray's test. These findings should however be interpreted with caution because only four studies were included. It was reported that Koonan et al. [18], Mirzatolooei et al. [19] and Goossens et al. [20] did not find the Thessaly test to be a valid and clinically useful test compared to Karachalios et al. [8]. Mirzatolooei et al. reported one of the lowest percentage of specificity $40 \%$ for the Thessaly's test compared to his McMurrays test values, which were very similar specificity and sensitivity values to three of the included studies $[8,18,20]$. In addition, six patients had to withdraw from Mirzatolooei study due to their knee giving way and severe pain during the Thessaly Test. This could be a factor as to why Mirzatolooei concluded that the Thessaly test was not clinically useful. Furthermore, research has revealed that concurrent ACL deficient knees have been shown to significantly lower the diagnostic accuracy of the Thessalys test [1]. Konan et al. [18] and Goossens et al. [20] studies also reported that the Thessaly's test was not clinically useful compared to Karachalios et al. [8]. This may be due to the fact that Konan et al. and Goossens et al. employed a cohort design, apart from a cohort study being a lower strength according the hierarchy scale of evidence [21], there may also be the possibly of a cohort study to be somewhat unbalanced and biased [18-20,22] compared to Karachalios et al., who employed a randomised, cross over design. Such a design ensures there is no bias in the testing of diagnostic accuracy and follows the appropriate methodology for assessing diagnostic tests [23]. In addition, Goossens et al. study only excluded patients if they had previous knee surgery in the last 3 months [20]. This however did not exclude patients who may have had surgery prior to the required 3 months. This could have influenced the outcome of the tests for patients who may have had ACL surgery or meniscal surgery.

All included studies confirmed a meniscal tear prior to clinical examination and surgery $[8,18-20]$. Although it is clearly documented in the literature that MRI is a gold standard in the diagnosis of a meniscal lesion, a study by Ercin et al. reported that clinical examination by an experienced clinician versus MRI showed only marginal differences in specificity and sensitivity values, therefore suggesting that MRI are not always required in the diagnosis of meniscal tears if an experienced clinician conducts a full clinical examination. In addition, Madhusudan et al. conducted a study investigating clinical examination versus MRI and found that clinical examination showed higher specificity values and MRI demonstrated a higher sensitivity value in the detection of meniscal tears, therefore suggesting that MRI should be used as more of a supplementary tool [24].

\section{Limitations of the included studies}

The range of patients in the included studies varied because of different methods in the patient recruitment process. Most obviously, the characteristics of the studies varied due to the differences in study inclusion and exclusion criteria and study design (randomised study versus diagnostic accuracy studies) $[8,18-20]$. The reference standards used in all studies was MRI and arthroscopy $[8,18-20]$, however MRI is not always as accurate as an arthroscopic investigation. Similarly, due to the invasive nature of knee arthroscopy or surgery as a reference standard may have affected the recruitment of participants through some of the included studies. Having used a clinical composite score which assesses five key subjective and objective meniscal related

\begin{tabular}{|c|c|c|c|c|c|c|c|c|c|c|c|c|c|c|c|}
\hline Article & $\mathbf{1}$ & $\mathbf{2}$ & $\mathbf{3}$ & $\mathbf{4}$ & $\mathbf{5}$ & $\mathbf{6}$ & $\mathbf{7}$ & $\mathbf{8}$ & $\mathbf{9}$ & $\mathbf{1 0}$ & $\mathbf{1 1}$ & $\mathbf{1 2}$ & $\mathbf{1 3}$ & 14 & Total \\
\hline $\begin{array}{c}\text { Karachalios et } \\
\text { al. [18] }\end{array}$ & $\checkmark$ & $\checkmark$ & $\checkmark$ & $\checkmark$ & $\checkmark$ & $\checkmark$ & $\checkmark$ & $\checkmark$ & $\checkmark$ & $\checkmark$ & $\checkmark$ & $U$ & $\mathrm{~N}$ & $\checkmark$ & 12 \\
\hline $\begin{array}{c}\text { Konan et al. } \\
\text { [19] }\end{array}$ & $\mathrm{N}$ & $\checkmark$ & $\checkmark$ & $\checkmark$ & $\checkmark$ & $\checkmark$ & $\checkmark$ & $\checkmark$ & $\mathrm{N}$ & $\checkmark$ & $\cup$ & $\checkmark$ & $\mathrm{N}$ & $\checkmark$ & 10 \\
\hline $\begin{array}{c}\text { Mirzatolooei et } \\
\text { al. [20] }\end{array}$ & $\checkmark$ & $\checkmark$ & $\checkmark$ & $\checkmark$ & $\checkmark$ & $\checkmark$ & $\checkmark$ & $\checkmark$ & $\checkmark$ & $\checkmark$ & $U$ & $\checkmark$ & $\checkmark$ & $\checkmark$ & 13 \\
\hline $\begin{array}{c}\text { Goossens et } \\
\text { al. [21] }\end{array}$ & $\checkmark$ & $\checkmark$ & $\checkmark$ & $\checkmark$ & $\checkmark$ & $\checkmark$ & $\checkmark$ & $\checkmark$ & $\mathrm{N}$ & $\checkmark$ & $\checkmark$ & $\mathrm{N}$ & $\mathrm{N}$ & $\checkmark$ & 11 \\
\hline
\end{tabular}

Table 3: QUADAS scores for the included studies. $\checkmark=$ yes; $N=$ no; $U=$ unknown.

\begin{tabular}{|c|c|c|c|c|c|c|c|c|c|c|c|c|c|c|c|c|c|c|}
\hline & \multicolumn{6}{|c|}{ Thessaly Test 5 degrees } & \multicolumn{6}{|c|}{ Thessaly Test 20 degrees } & \multicolumn{6}{|c|}{ McMurrays test } \\
\hline & \multicolumn{2}{|c|}{ Sensitivity } & \multicolumn{2}{|c|}{ Specificity } & \multicolumn{2}{|c|}{ Accuracy } & \multicolumn{2}{|c|}{ Sensitivity } & \multicolumn{2}{|c|}{ Specificity } & \multicolumn{2}{|c|}{ Accuracy } & \multicolumn{2}{|c|}{ Sensitivity } & \multicolumn{2}{|c|}{ Specificity } & \multicolumn{2}{|c|}{ Accuracy } \\
\hline & Medial & Lateral & Medial & Lateral & Medial & Lateral & Medial & Lateral & Medial & Lateral & Medial & Lateral & Medial & Lateral & Medial & Lateral & Medial & Lateral \\
\hline $\begin{array}{c}\text { Karachalios et al. } \\
{[18]}\end{array}$ & $66 \%$ & $81 \%$ & $96 \%$ & $91 \%$ & $86 \%$ & $90 \%$ & $89 \%$ & $92 \%$ & $97 \%$ & $96 \%$ & $94 \%$ & $96 \%$ & $48 \%$ & $65 \%$ & $94 \%$ & $86 \%$ & $78 \%$ & $84 \%$ \\
\hline Konan et al. [19] & \multicolumn{2}{|c|}{ No Data } & $68 \%$ & $89 \%$ & $49 \%$ & $71 \%$ & $59 \%$ & $31 \%$ & $67 \%$ & $95 \%$ & $61 \%$ & $80 \%$ & $50 \%$ & $21 \%$ & $77 \%$ & $94 \%$ & $57 \%$ & $77 \%$ \\
\hline $\begin{array}{l}\text { Mirzatolooei et } \\
\text { al. [20] }\end{array}$ & \multicolumn{6}{|c|}{ No Data } & \multicolumn{2}{|c|}{$79 \%{ }^{*}$} & \multicolumn{2}{|c|}{$40 \%{ }^{*}$} & \multicolumn{2}{|c|}{$60 \%{ }^{*}$} & \multicolumn{2}{|c|}{$51 \% *$} & \multicolumn{2}{|c|}{$91 \%{ }^{*}$} & \multicolumn{2}{|c|}{$56 \%{ }^{*}$} \\
\hline $\begin{array}{c}\text { Goossens et al. } \\
{[21]}\end{array}$ & \multicolumn{6}{|c|}{ No Data } & \multicolumn{2}{|c|}{$64 \%$} & $45 \%$ & $40 \%$ & $58 \%$ & $46 \%$ & $69 \%$ & $72 \%$ & $37 \%$ & $34 \%$ & $59 \%$ & $43 \%$ \\
\hline
\end{tabular}

Table 4: Diagnostic parameters reported in the included studies. * Not medial/lateral specific. 
outcomes, it is said to increase the positive predictive value of finding a meniscal tear by $92.3 \%$ [25].

All included studies lacked detail when describing the test procedure of the McMurray's test $[8,18-20]$. There are a number of variations of the McMurray's test [26]. The studies that compared the diagnostic accuracy of the McMurray's test with that of modified versions of the test showed enhanced diagnostic accuracy for the modified test. To ensure a more robust test procedure, thorough description of the McMurray's test may have minimised scrutiny over possible methodological flaws.

\section{Limitations of this review}

The QUADAS quality bias and checklist tool is heavily weighted towards assessing bias, as question items $3,4,5,6,7,10,11,12$ and 14 assess bias and two question items 1 and 2 are related to variability [4]. From an accuracy perspective, basing diagnostic values on specificity and sensitivity alone could be a limitation as heterogeneous nature of meniscal tears (anterior versus posterior tears) including different patient contexts and meniscal pathologies could dramatically alter levels of sensitivity and specificity values [27]. Okert et al. suggest that likelihood ratios are more of an accurate measurement for clinical diagnostic tests. Furthermore, only included studies which compared the Thessaly and McMurray tests were utilised, if all studies investigating the diagnostic parameters of these tests had been included it would have provided more conclusive data. A meta-analysis could not be performed due to the heterogeneous nature of the included studies.

\section{Implications for practice and future research}

This review has highlighted that there is currently a paucity of reasonable evidence comparing the Thessaly's test with the McMurray's test to determine a meniscal tear of the knee. Such research should ideally include randomised parallel group studies comparing the Thessaly's test with similar weight bearing meniscal tests such as the Ege's test [28]. To give a true representation of the population, research should be undertaken in patients that have both acute and chronic meniscal symptoms. In addition, future investigations should prospectively assess the value of commonly used aspects of the patient history and meniscus tests. Until such research is undertaken the clinical use of these interventions should be guided by sound clinical reasoning and practitioner experience.

\section{Conclusion}

This review systematically identified and appraised to create an evidence-based review for the diagnosis of a meniscus tear. Given that the Thessaly test and McMurray's test have the potential to assist in the diagnosis of a meniscal tear of the knee, the Thessaly's test appears underutilised in practice despite its potential advantages further research in this area is clearly warranted [29]. Although further diagnostic procedures such as MRI are important to confirm the diagnosis of a meniscal tear. MRI is useful, but should be reserved for situations in which an experienced clinician requires further information before arriving at a diagnosis. Indications for arthroscopy should be therapeutic, not diagnostic in nature [30]. The aim of this systematic review was to conclude the clinical usefulness of the Thessaly test in comparison to the McMurray's test in the diagnostic accuracy of a meniscal tear and from this it can be concluded the Thessaly test is an effective diagnostic tool that should be used within clinical practice.

\section{References}

1. McHale KJ, Park MJ, Tjoumakaris FP (2014) Physical Examination for Meniscus Tears. In: Kelly IVJD, editor. Meniscal Injuries: Springer New York 2: 9-20.
2. Nguyen JC, De Smet AA, Graf BK, Rosas HG (2014) MR imaging-based diagnosis and classification of meniscal tears. Radiographics 34: 981-999.

3. Pabbruwe MB, Kafienah W, Tarlton JF, Mistry S, Fox DJ, et al. (2010) Repair of meniscal cartilage white zone tears using a stem cell/collagen-scaffold implant. Biomat 31: 2583-2591.

4. LaPrade RF, Ho CP, James E, Crespo B, LaPrade CM, et al. (2015) Diagnostic accuracy of 3.0 T magnetic resonance imaging for the detection of meniscus posterior root pathology. Knee Surg Sports Traumatol Arthrosc 23: 152-157.

5. Ockert B, Haasters F, Polzer H, Grote S, Kessler MA, et al. (2010) Value of the clinical examination in suspected meniscal injuries: A meta-analysis. Unfallchirurg 113: 293-299.

6. Rinonapoli G, Carraro A, Delcogliano A (2011) The clinical diagnosis of meniscal tear is not easy. Reliability of two clinical meniscal tests and magnetic resonance imaging. Int J Immunopathol Pharmacol 24: 39-44.

7. McMurray TP (1942) The semilunar cartilages. BJS 29: 407-414.

8. Karachalios T, Hantes M, Zibis AH, Zachos V, Karantanas AH, et al. (2005) Diagnostic accuracy of a new clinical test (the Thessaly test) for early detection of meniscal tears. J Bone Joint Surg Am 87: 955-962.

9. Eren OT (2003) The accuracy of joint line tenderness by physical examination in the diagnosis of meniscal tears. Arthroscopy: The Journal of Arthroscopic \& Related Surgery 19: 850-854.

10. McHale K, Park M, Tjoumakaris F (2014) Meniscal Injuries: Management and Surgical Techniques. Springer Science.

11. Kim SJ, Hwang BY, Choi DH, Mei Y (2012) The paradoxical McMurray test for the detection of meniscal tears: an arthroscopic study of mechanisms, types, and accuracy. J Bone Joint Surg Am 94: e1181-1187.

12. Moher D, Liberati A, Tetzlaff J, Altman DG, Group P (2009) Preferred reporting items for systematic reviews and meta-analyses: the PRISMA statement. BMJ 339: 2535.

13. Whiting PF, Weswood ME, Rutjes AW, Reitsma JB, Bossuyt PN, et al. (2006) Evaluation of QUADAS, a tool for the quality assessment of diagnostic accuracy studies. BMC medical research methodology 6: 9.

14. Whiting P, Rutjes AW, Reitsma JB, Bossuyt PM, Kleijnen J (2003) The development of QUADAS: a tool for the quality assessment of studies of diagnostic accuracy included in systematic reviews. BMC medical dology 3: 25.

15. Whiting P, Rutjes A, Westwood M, Mallett S, Leeflang M, et al. (2014) Updating QUADAS: Evidence to inform the development of QUADAS-2.

16. Sharma UK, Shrestha BK, Rijal S, Bijukachhe B, Barakoti R, et al. (2011) Clinical, MRI and arthroscopic correlation in internal derangement of knee. Kathmandu Univ Med J (KUMJ) 9: 174-178.

17. Harrison BK, Abell BE, Gibson TW (2009) The Thessaly test for detection of meniscal tears: validation of a new physical examination technique for primary care medicine. Clin J Sport Med 19: 9-12.

18. Konan S, Rayan F, Haddad F (2009) Do physical diagnostic tests accurately detect meniscal tears? Knee Surg Sports Traumatol Arthrosc 17: 806-811.

19. Mirzatolooei F, Yekta Z, Bayazidchi M, Ershadi S, Afshar A (2010) Validation of the Thessaly test for detecting meniscal tears in anterior cruciate deficient knees. Knee 17: 221-223.

20. Goossens P, Keijsers E, van Geenen RJ, Zijta A, van den Broek M, et al (2015) Validity of the Thessaly test in evaluating meniscal tears compared with arthroscopy: a diagnostic accuracy study. J Orthop Sports Phys Ther 45: 18-24.

21. Gugiu PC (2015) Hierarchy of evidence and appraisal of limitations (HEAL) grading system. Eval Program Plann 48: 149-159.

22. Karachalios T, Hantes M, Zintzaras E (2011) Do physical diagnostic tests accurately detect meniscal tears? Knee Surg Sports Traumatol Arthrosc 19: 1226-1227.

23. Jaeschke R, Guyatt GH, Sackett DL (1994) Users' guides to the medical literature. III. How to use an article about a diagnostic test. B. What are the results and will they help me in caring for my patients? The Evidence-Based Medicine Working Group. Jama 271: 703-707.

24. Madhusudhan TR, Kumar TM, Bastawrous SS, Sinha A (2008) Clinical examination, MRI and arthroscopy in meniscal and ligamentous knee Injuries a prospective study. J Orthop Surg Res 3: 19 
Citation: Alexanders J, Anderson A, Henderson S, Clausen U (2016) Comparison of the Thesslay Test and McMurray Test: A Systematic Review of Comparative Diagnostic Studies. Physiother Rehabil 1: 104. doi: 10.4172/2573-0312.1000104

25. Lowery DJ, Farley TD, Wing DW, Sterett WI, Steadman JR (2006) A clinical composite score accurately detects meniscal pathology. Arthroscopy: The Journal of Arthroscopic \& Related Surgery 22: 1174-1179.

26. Hing W, White S, Reid D, Marshall R (2009) Validity of the McMurray's Test and Modified Versions of the Test: A Systematic Literature Review. Journal of Manual \& Manipulative Therapy 17: 22-35.

27. Shrier I, Boudier-Revéret M, Fahmy K (2010) Understanding the Different Physical Examination Tests for Suspected Meniscal Tears. Current Spor Medi Reports 9: 284-289.
28. Chivers M, Howitt S (2009) Anatomy and physical examination of the knee menisci: a narrative review of the orthopedic literature. JCCA 53: 319-333.

29. Zhoa R (2012) The thessaly's test is an accurate diagnostic tool in assessing meniscal tears Sanfransico. Spring Symposium California pp: 1-52.

30. Ryzewicz M, Peterson B, Siparsky PN, Bartz RL (2007) The diagnosis of meniscus tears: the role of MRI and clinical examination. Clin Orthop Relat Res 455: 123-133. 